\title{
Effects and Experiences of Families Following a Web-Based Psychosocial Intervention for Children with Functional Abdominal Pain and Their Parents: A Mixed-Methods Pilot Randomized Controlled Trial
}

This article was published in the following Dove Press journal: Journal of Pain Research

\author{
Rubén Nieto' \\ Mercè Boixadós (iD ${ }^{2}$ \\ Gemma Ruiz (iD) \\ Eulàlia Hernández (D) ${ }^{2}$ \\ Anna Huguet ${ }^{3}$ \\ 'eHealth Lab, Faculty of Health Sciences, \\ Universitat Oberta de Catalunya, \\ Barcelona, Spain; ${ }^{2}$ PSiNET Research \\ Group, Faculty of Psychology and \\ Education Sciences, Universitat Oberta \\ de Catalunya, Barcelona, Spain; ${ }^{3}$ IWK \\ Health Centre, Halifax, Canada
}

Purpose: To evaluate post-treatment efficacy of DARWeb (online psychosocial intervention for children with functional abdominal pain) using a randomized clinical trial design and combining quantitative and qualitative data.

Patients and methods: Twenty-five families with children with FAP in the experimental group (EG: accessed to DARWeb) and 36 in the control group (CG: wait-list) were compared. Children and parents completed measures of abdominal pain severity (primary outcome), quality of life, and satisfaction. Moreover, children completed measures of depression, functional disability, catastrophizing and coping strategies; parents completed measures about parental responses to their children's pain. Families also answered open questions and were interviewed. Results: A higher percentage of children in the EG achieved a significant clinical change in abdominal pain severity from the parents' perspective ( $28 \%$ in the EG vs $8.33 \%$ in the CG). There was a significantly greater reduction in pain frequency in the EG compared to the CG (both from the children's and parents' perspectives) from mixed repeated-measures analyses of variance (there was not a significant interaction in total scores of pain severity). A higher percentage of children in the EG improved in quality of life and depression compared to the CG (results from mixed methods repeated-measures analyses of variances were not significant). However, there were no differences for disability, pain catastrophizing or the coping strategies assessed from the children's perspective; neither from the parents' assessment of quality of life. There were significant interactions for parents' solicitousness responses and promotion of well behaviors in the expected directions. Families were quite satisfied with the intervention, and the qualitative results confirmed an improvement in pain and having learned important coping strategies.

Conclusion: Our results support the efficacy of our intervention, but future studies are needed with different profiles of initial severity of the pain problem, longer follow-ups, and other conditions.

Keywords: functional abdominal pain, web-based intervention, psychosocial intervention, children

\section{Introduction}

Functional abdominal pain (FAP) is a common problem in childhood, affecting up to $8 \%$ of the population. ${ }^{1}$ It can have a big impact on children, being frequently accompanied by comorbid mental health and other physical health problems. ${ }^{1,2}$ But
Correspondence: Rubén Nieto eHealth Lab, Faculty of Health Sciences, Universitat Oberta De Catalunya, Rambla Del Poblenou, I56, Barcelona 08018, Spain

Tel +34933263538

Fax +34933568822

Email rnietol@uoc.edu 
FAP also has a big impact on parents' health and wellbeing. ${ }^{3}$ Finally, its high prevalence and impact is also correlated with a high economic impact on society. For example, the economic impact of FAP and irritable bowel syndrome (IBS) in the Netherlands has been estimated to be over 2500 euros a year. ${ }^{4}$

Psychosocial interventions are the gold standard for children with chronic and recurrent pain and are also useful for children with FAP. ${ }^{5}$ However, despite the evidence of the efficacy of psychosocial interventions, around the globe there are very few services that offer psychosocial care to help children with pain and their families, and health care professionals receive little training in pain management. ${ }^{6-8}$

Information and communication technologies (ICT) represent an opportunity for facilitating access to evidence-based interventions at an affordable cost. Furthermore, ICT can increase autonomy and empower individuals to become more actively involved in their own care. ${ }^{9}$ For these reasons, their use is increasing in the health field in general, ${ }^{10,11}$ but also for people with chronic pain ${ }^{12,13}$ and children with pain specifically. ${ }^{14}$

ICT interventions include so-called web-based interventions $\left(\mathrm{WBI}^{15}\right)$ that have been shown to be effective for different health situations. ${ }^{16}$ Barak et $\mathrm{al}^{15}$ define a WBI as

... a primarily self-guided intervention program that is executed by means of a prescriptive online program operated through a website and used by consumers seeking health- and mental-health-related assistance. The intervention program itself attempts to create positive change and/ or improve/enhance knowledge, awareness, and understanding via the provision of sound health-related material and use of interactive web-based components.

In the pediatric pain field, studies have been conducted using WBI for children/adolescents with headache, ${ }^{17,18}$ juvenile idiopathic arthritis, ${ }^{19}$ and mixed pain problems (including children with FAP) ${ }^{20-23}$ Summarizing the evidence available, interventions have been found to be effective in reducing pain frequency, ${ }^{17,18,20}$ pain duration, ${ }^{17}$ pain intensity, ${ }^{18-22}$ activity limitations/pain interference, ${ }^{18,21-23}$ depressive and pain-related anxiety symptoms, ${ }^{18,23}$ maladaptive parent behaviors, ${ }^{18,22,23}$ parents' perceived impact, ${ }^{23}$ parents' miscarried helping, ${ }^{23}$ and pain catastrophizing. ${ }^{17}$ They have also been shown to increase sleep quality. ${ }^{22,23}$ However, despite the available literature, research in this area is still nascent and more evidence is needed.
We designed DARWeb, an innovative WBI rooted in the cognitive-behavioral model, to help change maladaptive thoughts and teach effective coping strategies and to help focus on living in accordance with values and objectives. ${ }^{24,25}$ Important novel points, with regard to the available literature, include: (1) it is a specific, tailored intervention for children with FAP, (2) it is almost completely self-directed (we only contacted families to send reminders and for technical problems), (3) it involves parents and children to the same degree (seven units for each member of the dyad), and (4) it is oriented toward secondary prevention, addressing important risk factors and focusing on children with non-severe recurrent abdominal pain problems. With our preliminary studies we found that families were quite satisfied with the intervention; they learned several coping strategies (and to give less importance to pain), and pain impact (severity and quality of life) was reduced coping strategies), and helping to focus on living in accordance with values and objectives. ${ }^{24,25}$

With the present study, we wanted to further investigate the effects of our intervention and increase the available evidence in this field. As in our previous research, we used qualitative data, but this time using a randomized clinical trial (RCT) design. This is because qualitative information can be useful in the context of randomized clinical trials in chronic pain in order to better understand and complement quantitative information. ${ }^{26}$ This is a novel point of this study as none of the abovementioned RCT studies performed in this field included extensive qualitative data.

The goal of this study was to evaluate the efficacy of DARWeb using an RCT design. We wanted to test posttreatment, short-term effects of our online psychosocial intervention (DARWeb) in a sample of children with FAP and their parents (comparing with a wait-list control group). Specifically, we wanted to test if it is effective in reducing pain severity and frequency, levels of disability and depression, and also in improving quality of life. We also wanted to test if the intervention facilitates the use of adaptive coping strategies, and responses, and reduces maladaptive thoughts. Finally, we wanted to gather experiences of families from their point of view and assess their satisfaction with the intervention to better understand their full experience.

\section{Methods}

An RCT comparing an experimental group (EG: receiving DARWeb intervention) with a control group (CG: wait-list 
group) was performed. This study can be considered a pilot RCT as it is the first one testing this intervention, and future RCTs could be performed including longer follow-ups, control conditions other than the wait-list, and larger sample size. Researchers were not blinded to the conditions assigned to each family. Families assigned to the EG were told that they would receive immediate access to the intervention while the ones in the CG would receive delayed access (access to the intervention was offered 11 weeks later). The RCT was registered at ClinicalTrials.gov (NCT02676232).

DARWeb has been briefly described in the introduction and many more details can be found in our previous works. $^{24,25}$ It consists of seven units for children and seven parallel units for parents (contents can be seen in Table 1), so it is designed for the whole family (requiring an equivalent amount of work for both children and parents). They were advised to complete one unit per week, and they had to complete the units in the order shown in Table 1. The units included written and multimedia materials that families had to complete on their own, as the intervention was designed to be self-directed. Our research team only sent reminders to families if they had not logged on to the system for 10 days.

DARWeb was implemented using the Intelligent Research and Intervention Software (IRIS) platform. ${ }^{27}$ This software allows professionals and researchers to create custom distance interventions and include their own

Table I Outline of the Contents for Parents and Children

\begin{tabular}{|l|l|l|}
\hline Unit & Parents & Children \\
\hline 1 & Basic information about FAP & Basic information about FAP \\
\hline 2 & $\begin{array}{l}\text { Pain mechanism, and } \\
\text { management of triggers }\end{array}$ & $\begin{array}{l}\text { Pain mechanism, and } \\
\text { management of triggers }\end{array}$ \\
\hline 3 & Setting SMART goals & Setting SMART goals \\
\hline 4 & $\begin{array}{l}\text { Parents' responses to child's } \\
\text { pain }\end{array}$ & Relaxation training \\
\hline 5 & $\begin{array}{l}\text { Training in assertive } \\
\text { communication }\end{array}$ & $\begin{array}{l}\text { Training in assertive } \\
\text { communication }\end{array}$ \\
\hline 6 & $\begin{array}{l}\text { Effects of parents' responses } \\
\text { to their own pain }\end{array}$ & $\begin{array}{l}\text { Identification and } \\
\text { management of negative } \\
\text { thoughts }\end{array}$ \\
\hline 7 & $\begin{array}{l}\text { Identification and } \\
\text { management of negative } \\
\text { thoughts }\end{array}$ & Distraction techniques \\
\hline
\end{tabular}

materials. An important feature of IRIS is that it allows the personalization of contents to users. For example, in DARWeb, we personalized contents including the name of the user and providing relevant examples from their inputs. IRIS also allows professionals and researchers to easily monitor user progress in the program.

\section{Procedure}

The study protocol was approved by the Ethics Committee of the Universitat Oberta de Catalunya as well as by a Spanish accredited clinical ethical committee (Regional Ethical Committee from the Community of Madrid). The study was conducted in accordance with the Declaration of Helsinki (Ethical principles for medical research involving human subjects). Families had to give their written informed consent to participate in accordance with the protocol approved by the Ethical Committee. Several pediatricians referred families who met inclusion criteria for our study. They introduced the study to the family, but a member from the research team contacted each family who showed initial interest in the study by phone to further explain the details of our study. If the family was interested and agreed to participate, an additional interview by videoconference was set up with each family.

Before this interview, families were randomized every time we had a group of six eligible families; a stratified randomization procedure ${ }^{28}$ was used, blocking gender and age with the objective of guaranteeing that the two groups had a similar percentage of boys and girls, and of younger (9 to 12 years) and older children (13 to 15 years). Within each block, simple randomization was performed using a random sequence generated by computer and performed in a way that was hidden to the researcher. We decided to use small groups, instead of waiting to have a complete list of all potential participants, to reduce as much as possible the time needed for families to access the intervention.

The aim of the interview (usually performed by videoconference) was to further explain details of the intervention, procedure, and assessment task required. Following the interview, they were asked to complete baseline assessments (M0 measures) that were implemented online using Limesurvey software. After 11 weeks, all families were asked again to complete assessments (post-intervention, M1 measures), and at this point families assigned to the CG were invited to take part in the intervention if they wanted to. M0 and M1 measures included standardized questionnaires and open questions. After completing DARWeb (all the units or until they were not willing to 
finish them), all families were interviewed by a member of the research team by videoconference using in-depth, semi-structured interviews (children and parents were interviewed together). These interviews lasted approximately 15 to 20 mins and were audio recorded.

\section{Participants}

Children with FAP from 9 to 15 years old and their parents were invited to take part in this study. The inclusion criteria were the ones proposed by Apley and Naish; ${ }^{29}$ that is, children (and their families) were invited to participate if they had had a minimum of 3 episodes of abdominal pain that interfered with their daily activities during the previous 3 months. Children with an organic cause for their abdominal pain or with a severe mental illness were excluded. These criteria were assessed by the pediatrician who referred them or confirmed by the participants during the initial interview with the research team. Children or parents who were unable to understand Spanish were excluded. We also excluded children who missed school for more than two days in the previous month as a consequence of abdominal pain. This is because this criterion has been found to relate to the level of pain disability, ${ }^{30}$ and we wanted to have a sample of children with non-severe pain problems.

Sample size was calculated using the formula proposed by Pita $^{31}$ when we designed the RCT. We used pain severity as a variable to calculate sample size as it was commonly used in prior studies. Specifically, prior studies have often compared the proportions of participants that achieve a clinically significant change in pain severity, considering that it occurs when there is a reduction of $50 \%$ or more in pain intensity. ${ }^{20,32,33}$ Using this criterion, and based on previous studies, it can be estimated that the approximate percentage of children experiencing a reduction of $50 \%$ or more in pain severity in the EG will be $50 \%$ and in the CG $15 \%$. In addition, we considered a significance level of 5\%, power of $80 \%$, and a percentage of losses of $15 \%$. Based on these parameters, a sample of 50 participants, 25 in each group, would be necessary to study the effects of the intervention. A sample such as this was also considered optimal as we wanted to combine quantitative and qualitative data, carry out an exhaustive evaluation of the effects and satisfaction, and achieve an in-depth understanding of families' experiences. Analyzing this data is complex and samples in qualitative studies are usually small.

\section{Measures}

\section{Quantitative Measures}

Variables and questionnaires for quantitative assessments (M0 and M1) were selected following the recommendations about the core outcome domains for clinical trials by the PedIMPACT. ${ }^{34}$ These measurements were the same for both assessments (M0 and M1), except for satisfaction with the intervention, and qualitative measures which were only collected only at M1.

\section{Primary Treatment Outcome}

Parents and children completed the Spanish version of the Abdominal Pain Index (API). ${ }^{35,36}$ This is composed of 5 items that assess abdominal pain frequency, duration, and intensity (typical and highest abdominal pain intensity) in the previous two weeks. The frequency of abdominal pain episodes is rated using a 6-point scale ranging from "not at all" (0) to "every day" (5). The typical daily frequency is also rated using a 6-point scale from "none" (0) to "constant during the day" (5). Typical duration of pain episodes is rated using a 9-point scale ranging from "none" (0) to "all day" (8). Finally, typical and highest abdominal pain intensity are rated using an 11-point rating scale from "no pain" (0) to "the most pain possible" (10). This instrument has been widely used in the literature, and its psychometric properties have proven to be adequate. Acceptable internal consistency indexes (0.76 for parent proxy report and of 0.73 for children with FAP), and test-retest reliability in a two-week follow-up (correlations of 0.59 for children with FAP) have been found. Likewise, good concurrent (correlation of 0.60 between scores from children's and parents' reports), discriminant (significant differences between children with FAP and children without) and construct validity (significant correlations with related constructs such as pain appraisal or pain disability, among others) were found both for children's and parents reports. ${ }^{37}$ We computed total API scores (on a scale from 0 to 50) as other researchers have done. ${ }^{38,39}$ We also analyzed responses from the first item as a separate indicator of pain frequency. This is an important parameter for children with FAP, and this single item has been used in previous studies. ${ }^{40,41}$

\section{Secondary Treatment Outcomes}

We used a short version of the Pediatric Quality of Life Inventory (PedsQL) questionnaire, a frequently used and highly recommended questionnaire. ${ }^{34}$ With this questionnaire, 
informants (parents and children in our study) are asked to rate, using a 5-point scale from "never a problem" (0) to "almost always a problem" (4), to what extent each of the items had been a problem in the previous month. Total scores can be computed and linearly transformed to a 0-100 scale. Psychometric properties for the version we used (that includes 12 of the original items) ${ }^{42}$ were adequate. More specifically, in a sample from the community, the internal consistency index was 0.76 . Construct (children with chronic pain had a lower quality of life compared to those who did not have chronic pain), convergent (significant correlations in the expected direction with a different scale assessing also quality of life), and predictive validity (significant correlations in the expected directions with interference on parents' daily routines and functional disability) were also supported. ${ }^{42}$

Children were asked to complete the Children Depression Inventory $\left(\mathrm{CDI}^{43}\right)$, which is one of the most commonly used instruments to assess depression and has shown adequate psychometric properties in the Spanish population. ${ }^{44,45}$ For example, in clinical and non-clinical populations, internal consistency was over than $0.80^{44,45}$, test-retest correlation (two weeks period) was 0.8 , and adequate concurrent validity was demonstrated with high correlation with other measures assessing depression. ${ }^{45}$ The CDI encompasses 27 items with three statements, each of which refers to a specific symptom. Children are asked to choose the one which best reflects their situation in the previous two weeks. Total scores can be computed after reversing some of the items' scores.

Children were also asked to complete the Functional Disability Inventory $\left(\mathrm{FDI}^{46}\right)$, which has shown adequate psychometric properties in the Catalan population. ${ }^{47}$ For example, internal consistency was found of 0.89 in a community sample. Convergent validity was supported with significant positive correlations with anxiety sensitivity and internalizing/catastrophizing behaviors; there were also negative significant correlations with quality of life. Moreover, there were significant differences in mean scores of those community children having chronic pain and those who did not. ${ }^{47}$ The FDI is composed of 15 items in which children were asked to rate on a 5-point Likert scale their difficulties in a variety of everyday activities. Total scores can be computed by summing up all the items.

\section{Satisfaction with Treatment}

At M1, children in the EG were asked separately to rate (using an 11-point numerical scale) their satisfaction with the intervention using the following global question: ${ }^{34}$ Considering pain reduction, potential inconveniences as a consequence of following DARWeb, performance in everyday activities, how do you feel, how you sleep, how things are in school and family life, to what extent are you satisfied with DARWeb? The same global question was adapted and formulated to ask parents their satisfaction. In addition to this global question, at the end of each unit (with 5 questions in DARWeb), parents and children were asked separately to rate to what extent (on an 11point numerical scale) they found the content to be useful and interesting, and the design attractive, and to what extent they felt they had learned important things and were satisfied with the unit.

\section{Process Variables}

We asked children to answer the children's version of the Pain Catastrophizing Scale (PCS), ${ }^{48}$ a 13 -item questionnaire in which children are asked to rate the different thoughts presented on the items on a 5-point from "never" (0) to "always" (4). The results of a previous study supported the adequate psychometric characteristics of this scale when used among the Catalan population and supported the computation of a global score from the individual items. Internal consistency index (Crombach's a) was 0.89 . Convergent (significant correlations in the expected direction with a different scale assessing also catastrophizing), discriminant (correlations between PCS scores and a different scale assessing also catastrophizing were greater than correlations between PCS and other scales assessing constructs different from catastrophizing), and criterion validity (significant correlations in the expected directions with anxiety sensitivity, disability, pain intensity, and some coping strategies) were also supported. $^{49}$

Children also completed the Pain-Coping Questionnaire $\left(\mathrm{PCQ}^{50}\right)$. It is composed of 36 items representing the use of different coping strategies rated on a 5-point scale ranging from never (1) to very often (5). From a study with a sample of Catalan schoolchildren, items can be grouped into seven different coping strategies: positive self-statements, seeking social support, behavioral distraction, cognitive distraction, externalizing, catastrophizing, and information seeking. Internal consistency for these scales was adequate, ranging from 0.69 to 0.87 . Validity of the different scales was also supported with the significant correlations and in the expected direction found with chronic pain, beliefs, and quality of life $\mathrm{e}^{51 .}$ 
Parents' responses to children's pain were assessed with the Inventory of Parent/Caregiver Responses to Children's Pain Experience (IRPEDNA ${ }^{52}$ ). This is composed of 37 items that reflect actions and behaviors that parents can enact in response to children's pain. Parents are asked to report how often they enact each reaction on a 5-point scale from "never" (0) to "always" (4). Items are grouped in three subscales reflecting different patterns of responses: (1) solicitousness, (2) discouragement, and (3) promotion of well behaviors and coping. Internal consistency of these three scales was good in a sample of parents from the community, ranging from 0.83 to 0.87 . Criterion validity was also supported with significant correlations with negative affect. ${ }^{52}$

\section{Qualitative Measures}

At M1 assessment, families were asked to complete the above-mentioned standardized questionnaires and also to answer 3 open questions (parents and children separately) through the online survey. The questions were: 1) Why are you satisfied (or not) with DARWeb?, 2) What is the most important thing you have learned from the program?, and 3) Which of the things you have learned have you used most frequently?

We also performed a semi-structured interview with each family. There was an outline, but the attitude of the interviewer was non-directive, giving families time and the chance to comment on themes not included in the agenda. Among the main topics included in the agenda for the interview were: (1) pain perceptions, (2) satisfaction and opinions about DARWeb, (3) burden (time required to follow the intervention), and (4) satisfaction with method of delivery.

\section{Data Analyses}

A per-protocol analysis approach (PPA) was applied to this study as has been used in other RCTs in children with recurrent/chronic pain. ${ }^{38,41,53-55}$ There were several reasons why we did this. First, and possibly most importantly, we wanted to understand the full experience of families by using qualitative and quantitative data. Quantitative data could be imputed for those families who at least completed the pre-assessment questionnaires. However, qualitative data could not be imputed if there was no follow-up. So, we used PPA to have the same approach for the analyses of the two sources of information and gain a comprehensive picture of families' experiences (combining both sources of information in the discussion section of this paper). Second, this study can be considered a pilot RCT that could help with the design of future studies. Third, some of the families allocated to the EG or the CG (see Figure 1) did not complete M0 measures (besides they agreed to participate and were contacted several times). This excluded them from intention-to-treat (ITT) analyses. However, in line with the work by Hicks, ${ }^{20}$ an ITT analysis (last observation carried forward) with families at least completing M0 measures was applied to the primary outcome to test differences in results. Equivalent results were obtained to the ones presented in the results section.

We tested differences in the percentage of families who achieved a clinically significant change in primary and secondary outcomes (API, PedsQL, CDI, and FDI scores). Based on previous research testing interventions for children with $\mathrm{FAP}^{39}$ we used the recommended reliable change index to test clinically significant changes. The proportion of subjects who achieved a clinically significant change was compared for EG and CG using chi-square tests. In addition to these analyses, mixed repeatedmeasures analysis of variance (ANOVA) (time $\times$ group) were computed for each outcome variable. This type of analysis has also been frequently employed in previous RCTs with children with FAP. ${ }^{38,56}$

For qualitative analyses, interviews and responses to open questions were analyzed separately by two members of the research team (MB and GR analyzed interviews; and GR and RN analyzed responses to open questions). An inductive, structured, content analysis procedure (following the classification in "Qualitative research and its place in psychological science" by Madill and Gough ${ }^{57}$ ) was applied using Atlas.ti 8.0 software. Sub-themes were defined by a preliminary exploration of the main pieces of content. These sub-themes were agreed upon and grouped into larger themes in different meetings. Once this was defined, the two members in charge of analyzing the materials independently classified the qualitative data into these different themes and sub-themes. Any disagreements were discussed until agreement was reached, and the structure (and composition) of themes and sub-themes was redefined when needed. We calculated the Cohen's kappa coefficient once the system of themes and subthemes for each kind of material was established, and the inter-coder agreement was over 0.76 in all the analyses performed. 


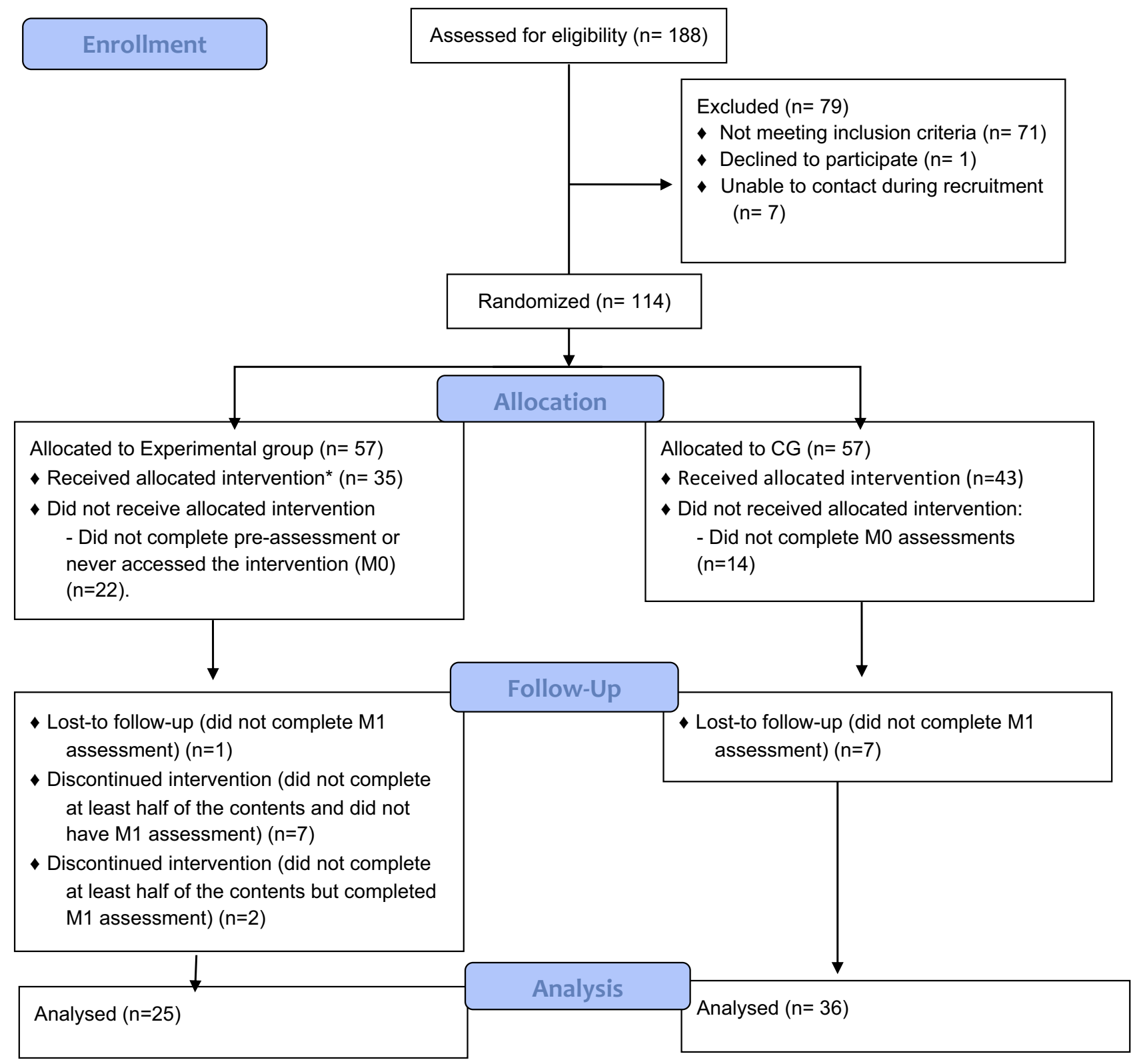

Figure I CONSORT flow diagram.

\section{Results}

\section{Quantitative Results}

\section{Sample Description}

There was a total of 25 families in the EG and a total of 36 in the $\mathrm{CG}$ (see Figure 1). Mean age for children in the EG group was $11.28(\mathrm{SD}=1.9)$, and $56 \%$ were girls. In the $\mathrm{CG}$, mean age was $11(\mathrm{SD}=1.47)$, and $52.8 \%$ were girls. There were no significant differences in mean age or sex proportion between groups (see Table 2 for descriptive statistics in relation to all measurements). There were significant differences in $\mathrm{M} 0$ measures for parents' total API scores $\left(\mathrm{t}_{(\mathbf{1}, \mathbf{5 9})}=2.48 ; \mathrm{p}=0.02\right)$ and API item number one $(U=-2.19 ; p=0.03)$. Total API scores were used as a covariate for mixed repeated-measures analysis of variance for parents' secondary outcome variables and process variables. For children's scores, there were no significant differences in any of the variables under consideration.

Of the 25 families in the EG, 14 (56\%) completed the whole program within 11 weeks of having access (the time at which families were asked to complete the M1 assessment). The rest of the families were usually working on the last units (between unit 6 and 7), or had finished at least half of the program, when they completed the assessments. All but two of the families finished the program after completing the assessments. 
Table 2 Sample Description

\begin{tabular}{|c|c|c|c|c|}
\hline \multirow[t]{2}{*}{ Measurement } & \multicolumn{2}{|c|}{ EG (Mean, SD) } & \multicolumn{2}{|c|}{ CG (Mean, SD) } \\
\hline & MO & MI & MO & MI \\
\hline API total (children) & $17.60(10.60)$ & $12.72(10.32)$ & $15.03(8.87)$ & II.55 (8.84) \\
\hline API total (parents) & $19.40(8.75)$ & I4 (8.44) & $13.86(8.43)$ & II.67 (8.93) \\
\hline API item I(children) & $2.32(1.86)$ & $1.08(1.32)$ & $1.60(1.42)$ & I.II (I.24) \\
\hline API item I (parents) & $2.16(1.67)$ & $1.28(1.21)$ & $\mathrm{I} .33(\mathrm{I} .33)$ & I.I7 (I.15) \\
\hline PedsQL (children) & $76(13.66)$ & $81.92(13.28)$ & 74.05 (16.09) & $77.95(|4.9|)$ \\
\hline PedsQL (parents) & $74.33(12.57)$ & $77.42(15.09)$ & $72.45(14.36)$ & 79.40 (13.29) \\
\hline CDI (children)** & $10.52(8.12)$ & $7.52(5.21)$ & $9.37(5.74)$ & $8.75(7.13)$ \\
\hline FDI (children)** & $10.32(8.73)$ & $5.96(6.25)$ & II.34 (I0.43) & $8.22(8.61)$ \\
\hline IRPEDNA Solicitousness* & $2.00(0.58)$ & $\mathrm{I} .26(0.59)$ & $1.96(0.69)$ & I.8I (0.76) \\
\hline IRPEDNA Distraction* & $0.61(0.51)$ & $0.48(0.42)$ & $0.74(0.5 \mathrm{I})$ & $0.56(0.4 I)$ \\
\hline IRPEDNA Well behaviors* & $2.58(0.6 I)$ & $2.89(0.71)$ & $2.72(0.59)$ & $2.6 I(0.77)$ \\
\hline $\mathrm{PCl}$ (children) ${ }^{* *}$ & $22.96(13.13)$ & $13.52(\mid 1.32)$ & $23.29(13.72)$ & $18.67(12.10)$ \\
\hline PCQ Positive Self-statements** & $2.75(1.16)$ & $2.68(1.22)$ & $2.47(1.03)$ & $2.55(1.14)$ \\
\hline PCQ Seeking social support** & $2.46(0.95)$ & $2.06(0.93)$ & $2.57(1.04)$ & $2.31(0.99)$ \\
\hline PCQ Behavioral distraction** & $2.90(1.21)$ & $3.06(1.14)$ & $2.51(1.15)$ & $2.83(1.20)$ \\
\hline PCQ Cognitive distraction** & $2.87(1.15)$ & $2.91(1.10)$ & $2.51(0.74)$ & $2.78(0.95)$ \\
\hline PCQ Externalizing** & $1.68(0.95)$ & $\mathrm{I} .52(0.65)$ & $1.43(0.55)$ & $\mathrm{I} .38(0.68)$ \\
\hline PCQ Catastrophizing** & $2.59(1.00)$ & $2.03(1.03)$ & $2.59(1.14)$ & $2.40(\mathrm{I} . \mathrm{II})$ \\
\hline PCQ Information seeking** & $2.64(0.94)$ & $2.55(0.92)$ & $2.57(0.83)$ & $2.57(0.82)$ \\
\hline
\end{tabular}

Notes: *Reported only by parents. **Reported only by children.

\section{Primary Outcome Variable}

From the children's perspective, there was a higher percentage of participants who reached the cut-off point for clinical change in total API scores. More specifically, 32\% of the children in the EG vs a $20 \%$ in the CG reported a decrease greater than 10.31 (cut-off point computed using the reliable change index) in total API scores. However, the differences were not significant (Chisquare $\left._{(1)}=1.12 ; \mathrm{p}=0.22\right)$. The same was true from the parents' perspective, but the differences were significant in this case. Specifically, 28\% in the EG reported a decrease greater than 10.50 in total API scores (Chi-square $(1),=4.16$; $\mathrm{p}=0.05$ ) and $8.33 \%$ in the CG.

Mixed repeated-measures ANOVA (time $\times$ group) were carried out to determine effects on total API scores and frequency of abdominal pain in the previous two weeks (item 1 from the API questionnaire). From the children's point of view, there was only a significant interaction effect $\left(\mathrm{F}_{(1.58)}=5.6 ; \quad \mathrm{p}=0.02 ;\right.$ partial eta square $=0.09$ ) for frequency of abdominal pain in the expected direction (abdominal pain episodes decrease significantly more for children in the EG group; see Figure 2). The same was true from the parents' perspective $\left(\mathrm{F}_{(1.59)}=5.3 ; \mathrm{p}=0.02\right.$; partial eta square $=0.08$; see Figure 3).

\section{Secondary Outcome Variables}

From the children's perspective, a significantly greater proportion of children in the EG achieved a clinically significant change in PedsQL scores (increase greater than 18.58 points in PedsQL scores: $36 \%$ EG vs $11.43 \%$ CG; Chi-square $(1)$ $=5.19 ; \mathrm{p}=0.02$ ). From the parents' perspective, percentages

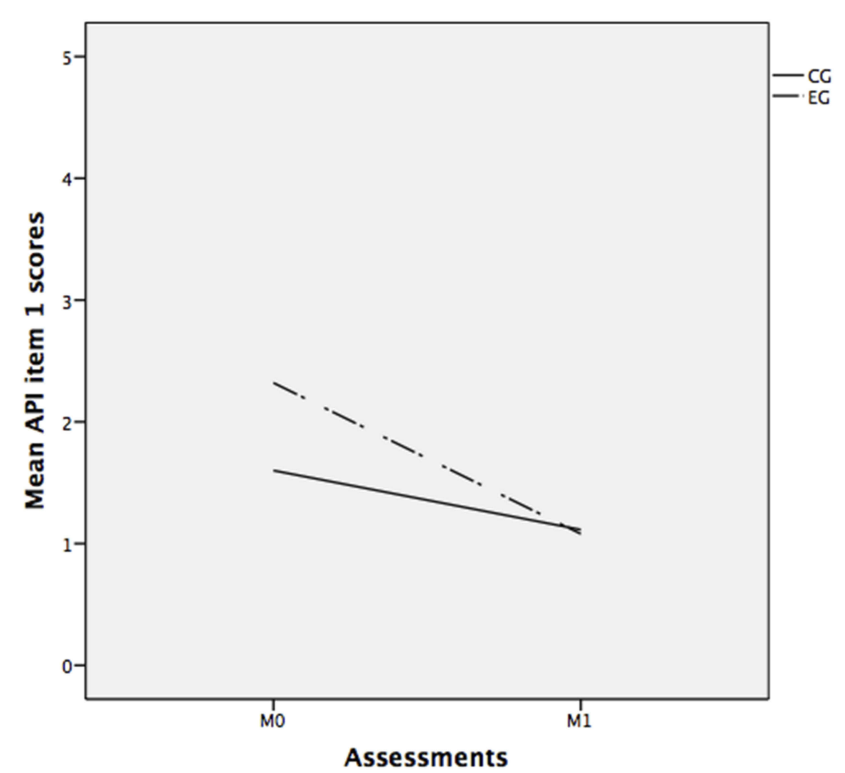

Figure 2 Significant interaction between conditions and time in frequency of abdominal pain from children's perspective (API item I). 


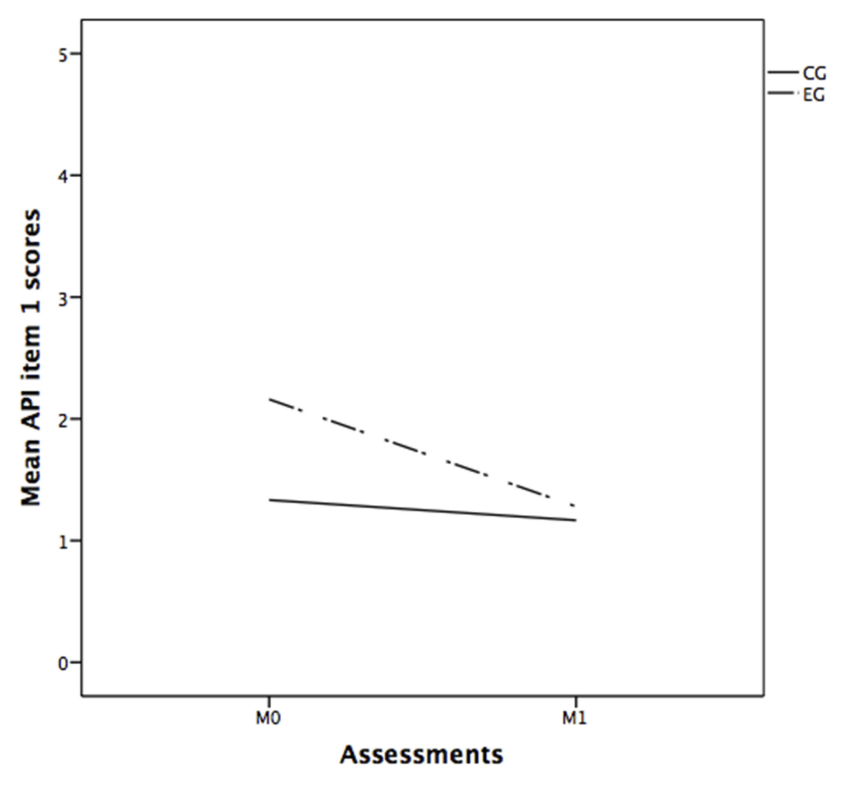

Figure 3 Significant interaction between conditions and time in frequency of abdominal pain from parents' perspective (API item I).

of children who achieve a clinically significant change were similar between groups (increase greater than 17.54 points in PedsQL scores: $12 \%$ EG vs $11.11 \%$ GC; Chi-square $(1)=0.01$; $\mathrm{p}=0.6$ ). The results of mixed repeated-measures ANOVA (time $\times$ group) did not yield any significant interaction for children's or parents' scores.

Nobody assigned to the CG achieved a clinically significant change in CDI scores (reduction in scores greater than 6.84$)$ whereas $16 \%$ of the children achieved it in the EG. The differences in proportions between the groups were statistically significant $($ Chi-square $(1)=6 ; \mathrm{p}=0.01$ ). From the mixed repeated-measures ANOVA, there were no significant group-by-time effects.

Finally, for FDI scores, $32 \%$ in the EG and $17.14 \%$ of the children in the $\mathrm{CG}$ achieved a clinically significant change (reduction in scores greater than 8.73), with differences that were not significant. There were no significant group-by-time interaction effects from mixed repeatedmeasures ANOVA.

\section{Satisfaction with Treatment}

Mean global satisfaction with treatment was 8.48 (SD: 1.23; range 6-10) for children and 7.67 for parents (SD: 1.52; range 5-10). Descriptive statistics from the five items relating to each of the seven units are presented in Table 3. As can be seen, mean scores were high for all units and aspects, both for children and parents. Ratings were slightly higher for parents in unit 5 (communication skills), and for children in units from 4 to 7.

\section{Process Variables}

For the scores in the PCS, although at descriptive level there was a higher decrease for children in the EG, there were not significant group-by-time interaction effects. The same was true for the coping strategies assessed by children, as there

Table 3 Descriptive Statistics from the Five Items Related to Each of the Seven Units

\begin{tabular}{|c|c|c|c|c|c|c|}
\hline & Useful & Interesting & Design & $\begin{array}{l}\text { Important } \\
\text { Things }\end{array}$ & Satisfaction & Mean Total \\
\hline Unitl & $\begin{array}{l}7.8(1.44) 7.6 \\
(2.00)\end{array}$ & $\begin{array}{l}8.16(1.34) 7.76 \\
(2.11)\end{array}$ & $\begin{array}{l}8.6(1.19) 7.88 \\
(2.05)\end{array}$ & $\begin{array}{l}7.6(1.63) 8.25 \\
(1.64)\end{array}$ & $\begin{array}{l}8.1(1.34) 8.28 \\
(1.72)\end{array}$ & $\begin{array}{l}8.06(1.17) 7.94 \\
(1.57)\end{array}$ \\
\hline Unit2 & $\begin{array}{l}8.08(1.19) 7.8 \\
(2.07)\end{array}$ & $\begin{array}{l}8.36(1.19) 7.48 \\
(1.96)\end{array}$ & $\begin{array}{l}8.36(1.22) 7.72 \\
(2.26)\end{array}$ & $\begin{array}{l}8.32(1.37) 8.28 \\
(2.32)\end{array}$ & $\begin{array}{l}8.2(I .38) 8.52 \\
(I .7 I)\end{array}$ & $\begin{array}{l}8.26(1.14) 7.97 \\
(1.66)\end{array}$ \\
\hline Unit3 & $\begin{array}{l}8.08(0.93) 8.36 \\
(1.8)\end{array}$ & $\begin{array}{l}8.21(0.98) 8.24 \\
(I .7 I)\end{array}$ & $\begin{array}{l}8(1.21) 8.08 \\
(1.94)\end{array}$ & $\begin{array}{l}8.21(1.25) 8.4 \\
(1.82)\end{array}$ & $\begin{array}{l}7.92(1.28) 8.84 \\
(1.86)\end{array}$ & $\begin{array}{l}8.08(0.95) 8.38 \\
(1.58)\end{array}$ \\
\hline Unit 4 & $\begin{array}{l}8.67(1.09) 8.75 \\
(1.59)\end{array}$ & $\begin{array}{l}8.62(1.09) 8.29 \\
(1.54)\end{array}$ & $\begin{array}{l}8.46(1.18) 8.21 \\
(1.79)\end{array}$ & $\begin{array}{l}8.58(1.14) 8.92 \\
(1.28)\end{array}$ & $\begin{array}{l}8.42(I .2 I) 8.7 I \\
(I .12)\end{array}$ & $\begin{array}{l}8.55(I .0 I) 8.57 \\
(I .3 I)\end{array}$ \\
\hline Unit 5 & $\begin{array}{l}8.91(1.04) 8.83 \\
(1.34)\end{array}$ & $\begin{array}{l}9.09(0.95) 8.42 \\
(1.86)\end{array}$ & $\begin{array}{l}8.74(0.91) 8.29 \\
(1.33)\end{array}$ & $\begin{array}{l}9.26(0.75) 8.96 \\
(1.08)\end{array}$ & $\begin{array}{l}8.52(1.34) 8.83 \\
(1.20)\end{array}$ & $\begin{array}{l}8.9(0.84) 8.67 \\
(1.09)\end{array}$ \\
\hline Unit 6) & $\begin{array}{l}8.48(0.99) \\
8.58(1.84)\end{array}$ & $\begin{array}{l}8.56(1.12) 8.5 \\
(1.50)\end{array}$ & $\begin{array}{l}8.48(0.99) 8.46 \\
(1.64)\end{array}$ & $\begin{array}{l}8.78(1.00) 8.83 \\
(1.66)\end{array}$ & $\begin{array}{l}8.43(1.04) 8.79 \\
(1.53)\end{array}$ & $\begin{array}{l}8.55(0.89) 8.63 \\
(1.46)\end{array}$ \\
\hline Unit 7 & $\begin{array}{l}8.83(1.07) 8.86 \\
(1.61)\end{array}$ & $\begin{array}{l}8.83(1.07) 8.77 \\
(1.57)\end{array}$ & $\begin{array}{l}8.65(0.98) 8.13 \\
(1.55)\end{array}$ & $\begin{array}{l}9(0.90) 8.73 \\
(1.52)\end{array}$ & $\begin{array}{l}8.61(0.94) 8.82 \\
(1.47)\end{array}$ & $\begin{array}{l}8.78(0.90) 8.66 \\
(1.43)\end{array}$ \\
\hline
\end{tabular}

Note: Mean (SD) in bold are from children's ratings. 


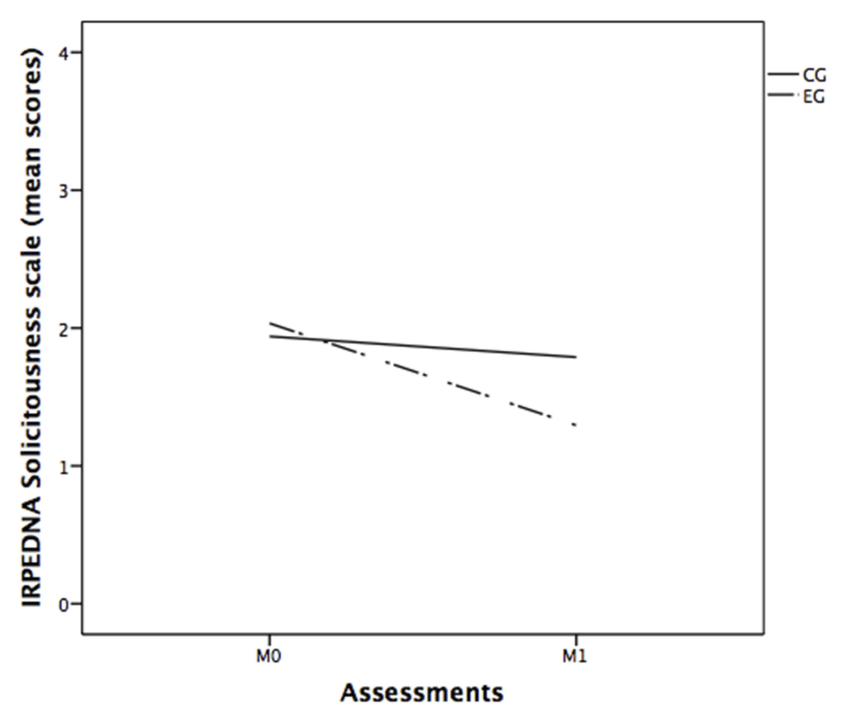

Figure 4 Significant interaction between conditions and time in solicitousness responses.

were no significant interactions for any of the coping strategies assessed. From the parents' assessment, there were significant group-by-time interaction effects for solicitousness responses, showing that those were reduced significantly

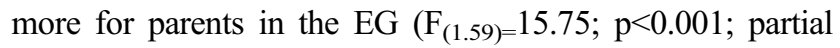
eta square $=0.21$; see Figure 4$)$. The interaction for the scale of promotion of well behaviors was also significant $\left(\mathrm{F}_{(1.59)}=8.11\right.$; $\mathrm{p}=0.006$; partial eta square $=0.12$; see Figure 5). Scores on this scale slightly increased in parents in the EG, whereas they slightly decreased in parents in the CG. Finally, the interaction was not significant for the Discouragement scale.

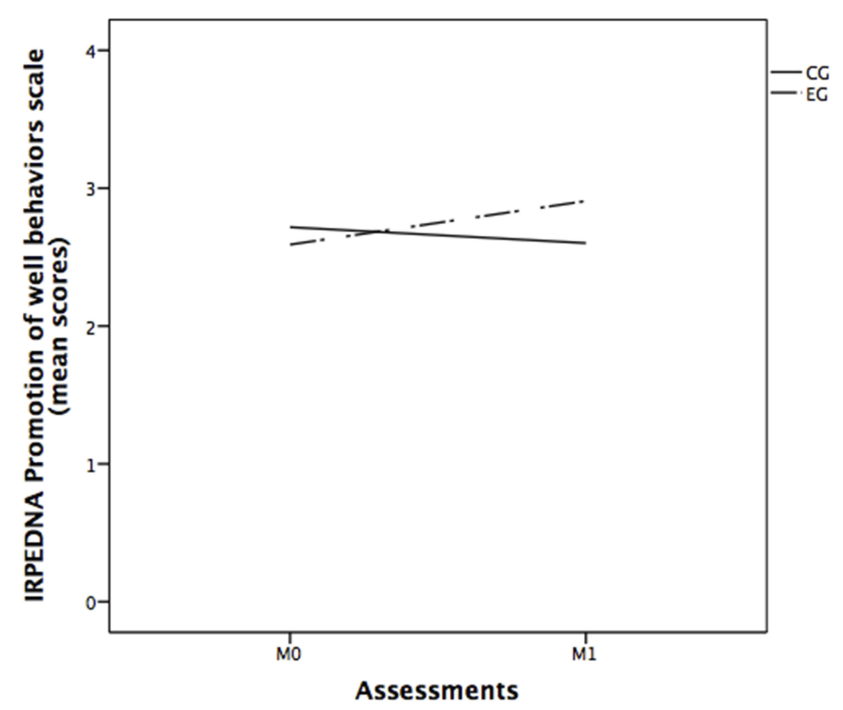

Figure $\mathbf{5}$ Significant interaction between conditions and time in promotion of well behaviors.

\section{Qualitative Results}

Five of the families in the EG were not available for the qualitative interviews, leaving a sample of 20 families ( $80 \%$ of the initial sample in the EG). They were contacted several times to arrange a meeting, but this was not possible due to other commitments. Table 4 shows the themes (and related sub-themes) identified. A full description of each theme is provided below. Information from the open questions complemented that provided by the families in the interviews on each theme.

\section{Satisfaction with DARWeb}

This theme covered all the comments made by families on the extent to which they were satisfied with the program. In the interviews, most families commented on the subtheme "Usefulness and general satisfaction" with the program (sub-themes are marked in this text in bold). This sub-theme included general comments relating to being happy to have had the chance to follow the intervention, to the perceived usefulness of DARWeb for their situation, and to attributing a high value to the intervention in general terms. As one father explained:

From our point of view, the program has been useful because it allowed us to confirm some things that we had experienced or seen [...] it has helped to guide us on what things we have done well or not so well.

In open questions, when they were asked about reasons for their satisfaction, both children and parents separately made frequent comments within this sub-theme. For example, one girl (12 years old) wrote: "I liked DARWeb very much, there are a lot of things I have applied to my abdominal pain."

Families also explained in interviews that they would recommend directly or have mentioned the intervention (as a positive option) to people around them ("DARWeb recommendation"). For example, one mother said:

Yes, we have done so, because we have therapy at [health care center name] for anxiety, and for fears and anxieties, and we told the group that we were using DARWeb. Some of them already knew about it, and others found it interesting. The psychologist already knew about it.

Similarly, after participating in DARWeb, some families commented that they would participate again ("Would participate again") even if they had not participated previously. For example, one mother said: "Yes, we would participate again. We are happy, above all else because we have found out about what it is [referring to FAP]." 
Table 4 Codes Interpreted as a Result of Content Analysis of in-Depth Interviews and Open Questions

\begin{tabular}{|c|c|c|c|c|}
\hline \multirow[t]{2}{*}{ Satisfaction with DARWeb } & \multirow[t]{2}{*}{$\%$ Family Interviews } & \multicolumn{3}{|c|}{ \% Open Questions } \\
\hline & & Satisfaction & More Important & Most Used \\
\hline $\begin{array}{l}\text { Usefulness and general satisfaction } \\
\text { Recommend DARWeb } \\
\text { Would participate again } \\
\text { Feeling reflected and understanding the problem } \\
\text { Comic stories } \\
\text { Not feeling reflected } \\
\text { Too much reading } \\
\text { Boring and repetitive } \\
\text { Difficult to understand } \\
\text { DARWeb improvement }\end{array}$ & $\begin{array}{l}95 \\
70 \\
50 \\
50 \\
35 \\
30 \\
35 \\
20 \\
15\end{array}$ & $\begin{array}{l}52 / 52 \\
24 / 8 \\
0 / 4 \\
4 / 0 \\
4 / 8\end{array}$ & $24 / 8$ & $0 / 4$ \\
\hline $\begin{array}{l}\text { Burden } \\
\text { Time established correctly } \\
\text { Time supervision } \\
\text { Difficulties in finding time }\end{array}$ & $\begin{array}{l}80 \\
35 \\
50\end{array}$ & & & \\
\hline $\begin{array}{l}\text { Pain perception and skills } \\
\text { Pain reduction } \\
\text { Feeling better } \\
\text { Relaxation techniques } \\
\text { Coping strategies } \\
\text { Giving less importance } \\
\text { No pain reduction } \\
\text { Positive thinking } \\
\text { Communication skills } \\
\text { Change negative thoughts } \\
\text { SMART } \\
\text { Distraction } \\
\text { Self-control } \\
\text { Empowerment } \\
\text { Not applying learning }\end{array}$ & $\begin{array}{l}90 \\
45 \\
70 \\
15 \\
\\
25 \\
20 \\
10 \\
70 \\
15 \\
45\end{array}$ & $\begin{array}{l}20 / 16 \\
8 / 32 \\
12 / 8 \\
28 / 16 \\
16 / 0 \\
\\
8 / 4 \\
8 / 0 \\
4 / 0\end{array}$ & $\begin{array}{l}16 / 48 \\
32 / 12 \\
24 / 12 \\
8 / 0 \\
4 / 4 \\
8 / 4 \\
0 / 4 \\
0 / 20 \\
48 / 0\end{array}$ & $\begin{array}{l}52 / 76 \\
8 / 4 \\
28 / 4 \\
4 / 4 \\
36 / 0 \\
12 / 0 \\
0 / 4 \\
20 / 4 \\
0 / 4 \\
20 / 0\end{array}$ \\
\hline $\begin{array}{l}\text { Satisfaction with online interventions } \\
\text { Online method satisfaction } \\
\text { Tech problems }\end{array}$ & $\begin{array}{l}95 \\
50\end{array}$ & & & \\
\hline
\end{tabular}

Notes: Numbers refer to percentages of families (for interviews), children or parents (for open questions), that mentioned each theme. Bold numbers represent children's percentages.

Families commented in interviews that they could identify with the pain/situation described in the information and that they realized that more people had the same problem. Moreover, they felt that the information helped them with their abdominal pain, and they experience relief when they could relate their pain to the information given in the contents ("Feeling reflected and understanding the problem"). For example, one mother said:

When you do not know what it is and you go around from one place to another. And when you see that it is something related to stress or psychological, you already feel calmer and you know there are things to mitigate it, so it is not so strong. I was just happy, seeing him not having pain every day.
Likewise, in reply to the open questions, families wrote about this issue (parents wrote about it more frequently). For example, one mother wrote: "Also, the fact that we have realized that it does not only happen to her and that it is not so severe." However, some families also mentioned in the interviews that they were not able to completely identify with the pain described in the information because, in their case, pain intensity and the consequences were not so serious ("Not feeling reflected"). For example, one boy (11 years) said: "[the intervention] explained to us [from contents and examples] that I could not have done hardly any activities and I have done almost all the activities I had." His father further explained: "To some extent, 
it was assumed [in the intervention] that children with this pain stop doing activities and in our case, our son has not stopped doing his activities."

The "Comic stories" sub-theme was also mentioned by families in the interviews. They highlighted being satisfied with graphic resources and especially with the comic scenes (the main character was Alex, a child with RAP) that we used to introduce the different topics. However, there were also some features that need to be improved based on their comments in the interviews. They commented that there was "Too much reading", that content (related to the intervention or the assessments) was too long, boring and/or repetitive ("Boring and repetitive") or difficult to understand ("Difficult to understand"). For example, one boy (14 years old) said: "Some units were too long, I would make them shorter", and one father said: "I have the feeling that in some points it was very redundant, maybe the same things are repeated a lot." In reply to the open questions, one parent and two children also wrote (or made ambiguous statements) about the need to introduce general improvements to the program but without specifying ("DARWeb improvement"). In general terms, as can be seen in Table 4, positive aspects related to DARWeb were much more frequent than those reflecting negative aspects.

\section{Burden}

This theme included comments about the time required to complete the units and tasks related to the intervention (there were comments about this only in interviews). Most of the families commented that they were able to keep to the program each week, and it was not perceived as an excessive burden. Or they commented that planning was needed but it was reasonable ("Time established correctly" sub-theme). For example, one girl (10 years old) explained: "Every week I was doing it, except for a week when I did it during the weekend." Her father also confirmed that: "Generally speaking, it can be completed fine." However, families also commented on their difficulty in keeping to DARWeb or filling out the evaluations at particular times as a consequence of difficulties coordinating work, family time and school work, or simply commented that they did not have enough time ("Difficulties in finding time"). For example, one girl (15 years old) said: "Some activities that were proposed such as keeping a diary or writing something ... I did not do them because I did not have time, I think they are a good proposal, but not everybody can do it."
Finally, some parents explained that they had to supervise their children and help them complete DARWeb; they also needed to remind their children to complete DARWeb (and sometimes they needed to be reminded themselves by the research team to keep to the intervention) ("Time supervision"). For example, one father said:

At times, there were moments when he did not want to do the work and we told him 'come on, let's go, let's set ourselves to it' and he said 'no, I don't want to' and then I said then 'let's get on with it seriously, we have to improve'.

\section{Pain Perception and Skills}

During the interviews and responses to open questions, families commented specifically about their perceptions about pain and about the skills they have gained. Specifically, most of them mentioned in interviews that they had experienced a pain reduction and were happy not having pain anymore or having it reduced since starting DARWeb ("Pain reduction"). For example, one mother commented: "Now she feels perfect, when it disappeared [referring to abdominal pain], she changed her mentality and now everything is fine, she is $100 \%$ again, she is back to her normal life at $100 \%$." Similarly, some parents and children (especially children) commented in reply to the open questions about feeling better in general without specifying pain ("Feeling better"). For example, one girl (12 years old) wrote: "Things have improved since we started." In contrast, very few families stated that they had not experienced a pain reduction ("No pain reduction"). For example, one girl (14 years old) commented: "It is still the same as it was in the beginning. It appears suddenly and gradually, it lasts an hour or so."

Based on the interviews, the specific coping techniques that were most commonly described as useful by families were relaxation and breathing techniques ("Relaxation techniques"), and distraction techniques ("Distraction"). As one father explained: "The relaxation unit, we do it a lot here at home, and distraction, it is one of the things that works most for us, helping forget the stomachache and doing things." Responses to the open questions, especially by children, reaffirmed families' satisfaction with these skills. For example, one boy (10 years old) wrote that the thing he had used most frequently in the program was "the exercise of stretching and then relaxing different parts of my body". Other specific coping strategies mentioned in the interviews and responses to the open 
questions were the "Communication Skills" sub-theme and the "Change negative thoughts" sub-theme. In this case, parents wrote more about these two specific coping skills in their replies to the open questions than children; one example was what a mother wrote about what she had used most frequently from DARWeb: "I try, although it is not always easy, to communicate assertively and, as I said before, to divert attention from certain recurrent thoughts." Finally, some families also spoke about the "SMART objectives" sub-theme.

Other families also commented in the interviews and responses to open questions (especially parents) that the techniques learned had helped them, but without specifying one or mentioning several of them together ("Coping strategies"). For example, one mother said:

When he has a stomachache, I tell him to relax, distract himself, breathe $\ldots$ because when you don't know what to do, you feel a bit helpless. Assertiveness is also very helpful to communicate a little bit. I tell him to read a book and he gets distracted right away.

Similarly, some families (and especially parents in responses to open questions) highlighted that DARWeb had empowered them to understand and help their children ("Empowerment"). For example, one mother wrote: "I have gained confidence in myself and sensibility about my daughter when she explains her fears to me". Likewise, families, and especially children in responses to open questions, commented that DARWeb had helped the children increase their control over themselves, their emotions, reactions or pain ("Self-control"). For example, one girl (12 years old) commented: "Knowing myself and know how to control myself."

Apart from pain reduction and learning useful strategies, families also mentioned in the interviews and responses to open questions the fact that they had changed their mentalities, they were not so frustrated when pain episodes took place and they had learned to get on with their lives despite the pain ("Giving less importance to pain"). For example, one father said:

I think the program has been useful for us to have some resources and not to make a mountain out of a molehill with these stomachaches. Knowing what it is, that it is something we live with and which should not overwhelm us excessively.

Similarly, some parents and children also commented in response to the open questions that DARWeb had given them a positive outlook ("Positive thinking"). For example, one mother wrote that the most important thing she had learned was "To be more patient and optimistic."

It was noteworthy that some parents and children commented in the responses to the open questions that they had not applied what they had learned ("Not applying learning"). For example, one mother wrote: "My child understands the program but I don't think he is not yet applying what he is learning yet."

\section{Satisfaction with Online Intervention}

A last theme, mentioned only in the interviews, was about the method of delivery of the intervention. Most of the families were happy to have completed DARWeb online. They stated that the possibility to do it online intervention was an advantage and made it easier to complete the program; they also considered it a flexible and convenient option ("Online method satisfaction" sub-theme). For example, one mother said:

The fact that you are doing it at your house, it allows children that are shy to work on it more from their point of view. But, in this sense it is good, because they are in their own environment, for example, in a group therapy session there are children that feel inhibited. He can do it at his own pace, even if he does not want me to be with him because he is embarrassed, when they are ready, you will see if they are doing it right or not. [...] you can do it when you want, when you are relaxed.

Despite showing satisfaction with the online delivery, half of them experienced and mentioned having had some minor technical difficulties, the most common being problems viewing and downloading videos or listening to audio ("Tech problems" sub-theme). For example, one mother said: "It did not let me to listen to Alex's story and every time I changed the scene I had to close it and open it again."

\section{Discussion}

The results of this study provide important data about the effects of completing an online psychosocial intervention for children with FAP and their parents, taking into account outcomes from the main actors involved and different perspectives. The results add to the emerging literature on WBI for pediatric pain. In this section, we will discuss our results taking into account prior studies conducted to test psychosocial interventions for children with abdominal pain which have used measures that coincide with the ones we used. 
In terms of the primary outcome, significant effects were found in families following the intervention. A higher percentage of children in the EG achieved a significant improvement in pain severity using a reliable change index as criterion from the parents' perspective (the same tendency was found from the children's ratings but differences were not significant). Moreover, a significant greater reduction in the frequency of abdominal pain episodes was found (both from the parents' and children's perspectives) among those who received the intervention in comparison to those who did not (no such effect was found for total API scores). The qualitative results reinforced this result as most families reported experiencing a pain reduction and some of them spoke about feelings of general improvement. Most of them also commented on a change in the perception of the role of pain in families' lives as they learned to give less importance to pain. This is something that we purposely stressed in the contents of our program (see Nieto et $a{ }^{58},{ }^{58}$ for extensive discussion of this). The percentages of improvement in API scores were quite similar to those found by van der Veek et $\mathrm{al}^{39}$ who used the same questionnaire. They found that $31.8 \%$ of the children with FAP improved or had recovered (computing the reliable change index, as we did) at post-treatment. The percentage increased at the 6- and 12-month follow-ups (51.2\% and $60 \%$, respectively). However, they did not find significant differences in the percentage of the group receiving cognitive behavioral therapy (CBT) in combination with intensive medical care (IMC) compared to the group only receiving IMC. Robins et $\mathrm{al}^{38}$ used total API scores to test differences between a group receiving a combination of CBT and standard medical care (SMC) versus a group only receiving SMC. They found that the group receiving CBT and SMC reported significantly less abdominal pain severity (from child and parent reports) than the group only receiving SMC at post-treatment and at the 6- and 12-month follow-ups.

Other studies have also used the API but tested specific psychosocial techniques for the management of FAP instead of an extensive CBT program. Wallander et $\mathrm{al}^{41}$ found a significant reduction in abdominal pain episodes for a group following writing therapy (in comparison to an SMC group) at the 6-month follow-up (effects were not significant at the 3-month follow-up). Van Tilburg et al ${ }^{59}$ tested an audio-recorded guided imagery treatment and computed a composite score from two items of the API (item to assess frequency and item to assess usual pain intensity). With this index, $63.1 \%$ of the children who completed the intervention achieved an improvement equal to or greater than $50 \%$ (significantly greater than the improvement in the CG receiving SMC) at postintervention. From our point of view, and taking into account the results mentioned, initial severity of children's FAP is an important factor in mediating the results in different trials. In our study, initial mean severity, as assessed by the API, was lower than reported in prior available research. For example, mean scores (preintervention) in the study by van der Veek $^{39}$ were 32.18 , while in our study mean scores were 17.60 (in both studies from the children's perspective). It is likely that children with greater initial severity recognize improvements more easily and engage more in interventions. In relation to this, some families in our study explained they did not see themselves reflected by the situation, as their pain problem was not so severe. In any case, studies that test interventions for children with different ranges of pain severity are needed, and we need to make more efforts to improve interventions and make them meaningful for all the participating families. The use of different time-frame measurements for assessments is also a key factor that probably increases heterogeneity in the results. From the above-mentioned studies, it seems that improvement is greater in medium- and long-term follow-ups. Finally, the diversity of treatment designs (all of those mentioned are from a psychosocial perspective but with a different focus), and the different conceptualization of a significant change in the different studies are also variables that increase heterogeneity and make it difficult to extract firm conclusions. This difficulty is also present in research about the efficacy of psychosocial therapies for other pain problems. ${ }^{33}$

In relation to secondary outcome variables, a significant improvement was observed in quality of life only from the children's perspective when comparing percentages of children who achieved a clinical change. The same was true for depression but not for disability. However, differences were not significant from parents' data assessments of quality of life, and results were not significant in any of the secondary outcomes assessed when using mixed repeated-measures ANOVA. In terms of the qualitative data, families did not comment specifically about these three outcomes (there were only some comments about "feeling better"). Similar results were found in the study by Hicks et $\mathrm{al}^{20}{ }^{20}$ testing an online psychosocial intervention for children with pain (including 
children with FAP) and using the PedsQL to assess quality of life. Their sample had initial scores in quality of life similar to ours, and they did not achieve a significant change at the 1- or 3-month follow-ups (either from the parents' or children's perspective). In contrast, in other studies with the same instrument, lower initial scores were reported (indicating worse quality of life in their sample), and they found greater significant improvement in experimental groups receiving CBT interventions than in the control group. ${ }^{55,56}$ It seems, as was the case with abdominal pain severity, that the higher the initial level of quality of life, the harder it is to find significant changes. Fewer studies have used the CDI and/or the FDI to assess outcomes in trials with children with abdominal pain. Levy et $\mathrm{al}^{60}$ used the same questionnaires as we used to assess depression and disability, and (as with our results) did not find a significant interaction from the children's assessment (at any of the three assessments: 1, 3, and 6 months) comparing children who received social learning and cognitive-behavioral therapy (SLCBT) to a group who received an education support (ES) condition. The study by van der Veek ${ }^{39}$ also failed to find any differences in FDI scores comparing the group receiving CBT and IMC to the one receiving only IMC. In short, results seem to be consistent in not finding clear effects on these outcomes and, therefore, further research is needed.

Satisfaction with the intervention, which is also an important outcome, ${ }^{34}$ was quite high both for parents and children. They gave mean scores above 7.5 for the global perception of change and also for the seven different units. With regard to the qualitative data, they also described general satisfaction with the program in general and with specific aspects. On the negative side, there were some families that commented that they did not feel reflected, or that there was too much content to read, and that it was also repetitive in some parts. These are important points to bear in mind in further developments of our program. Although we have introduced some improvements after our initial testing, ${ }^{24}$ we need to work further on more interactive and multimedia content. Despite this, they were quite satisfied with the online method, the time required for the intervention was set correctly, and few difficulties were mentioned.

In relation to process variables, there were no significant changes in catastrophizing or in any of the coping strategies from the children's assessments. However, there were significant differences in parents' responses to children's pain. Specifically, solicitousness responses decreased and promotion of well behaviors increased significantly. Qualitative data provided much more information about changes in coping strategies and perceptions. Specifically, families found interesting to manage pain relaxation techniques (children tended to mention it more than parents), as well as distraction strategies and communication skills (mentioned in particular by parents). Moreover, parents commented that they had learned important things about managing their children's pain (empowerment), which could be linked to the findings on the reduction in solicitousness responses and the increase in promotion of well behaviors. Similarly, Levy et $\mathrm{al}^{60}$ also found reductions in solicitousness responses; however, they also found significant improvements in some coping strategies from children's ratings. It is likely that our small sample size and the time frame of our assessments have contributed to not finding significant results, bearing in mind that the qualitative data produced salient comments about coping strategies and children also commented about having gained self-control.

Our study has some limitations. First, a long-term follow-up comparing families in the two conditions would have been very useful to see whether families receiving the intervention improved significantly more than those that did not receive it in the medium and long term. Second, the sample size is small, so it would be pertinent to replicate the results found here with larger samples. Third, as commented throughout the discussion, children had low levels of pain severity and impact compared to prior studies. This is one strength of our research as the results show that our intervention can probably help families before they develop a severe problem. However, it would also be interesting to replicate our findings with children with moderate/severe FAP and pain impact, and work on adapting the contents to different pain situations.

\section{Conclusions}

In short, after following a WBI intervention, children with FAP improved their perceived pain severity, as explained by families qualitatively and as partially found in the quantitative results. DARWeb is also probably beneficial in helping reduce the impact of FAP, as there were some effects on quality of life and depression from the children's perspective, but more research is needed to confirm these results. Families also learned important coping strategies that helped them to manage pain, and parents also felt empowered and learned how to respond to pain.

This research adds to the available emerging literature about WBI for children with pain and provides evidence of 
positive effects with some innovations. This is the first condition-specific intervention for children with FAP. It is almost completely self-directed and involves the whole family with a focus on secondary prevention. Another relevant point is the examination of families' experiences from a mixed-methods perspective. Future work is required to replicate results with children with a different level of initial pain severity. This work should involve longer term follow-ups and aim to improve our intervention on the basis of the results obtained.

\section{Data Availability}

The data used for the results presented in this manuscript (including individual ratings for items and total scores for each deidentified participant) are available from the corresponding author following a reasonable request (signing an agreement may be required) during the year after the publication of this manuscript.

\section{Acknowledgments}

We are very grateful to the individual professionals and collaborating centers that facilitated contact with participating families and helped us with the project. They include ABS. Girona 3; CAP Castellar del Vallès; CAP Cunit; CAP Montilivi. Girona; CAP Taradell; CAP Sant Vicenç de Montalt; CAP Sardenya; Centre Clínic Menorca, Barcelona; Centre Sanitari de l'Anoia; Centro de Salud Alcañiz; Centro de Salud García Noblejas; Centro de Salud Doctor Castroviejo; Centro de Salud María Jesús Hereza; Clínica Diagonal, Barcelona; Consorci d'Atenció Primària de Salut de 1'Eixample; Corporació de Salut del Maresme i la Selva; Fundació Althaia, Manresa; Hospital CIMA Sanitas; Hospital de Nens, Barcelona; Hospital Vall d'Hebrón; Hospital Trias i Pujol; Hospital de Figueres; Hospital Verge de la Cinta de Tortosa; Hospital Mútua de Terrassa; Hospital General de Granollers; Hospital Sant Joan de Reus; Paidodex. Hospital Quirón-Dexeus; PIUS Hospital de Valls; Policlínica Comarcal de El Vendrell; SAP Alt Penedès - Garraf - Nord. We are also very grateful to the families who participated in this study. We acknowledge that some sections of DARWeb are based on myWHI (an Internet-based CBT intervention for youth with headaches led by Drs. McGrath and Huguet) and the Strongest Family Program (distance family interventions for youth led by Drs. McGrath and Lingley-Pottie). This work was supported by Fundació La Caixa (RecerCaixa, 2012-2013) and the Ministerio de Economía y Competitividad (Spanish Government, Ref: PSI2013-42413-R; 2014-2017).

\section{Disclosure}

The authors report no conflicts of interest in this work.

\section{References}

1. Levy RL, Van Tilburg MAL. Functional abdominal pain in childhood: background studies and recent research trends. $\mathrm{Am}$ J Gastroenterol. 2012;17(6):413-418.

2. Galdston MR, John RM. Mind over gut: psychosocial management of pediatric functional abdominal pain. J Pediatr Heal Care. 2016;30 (6):535-545. doi:10.1016/j.pedhc.2015.11.011

3. Calvano C, Warschburger P. Quality of life among parents seeking treatment for their child's functional abdominal pain. Qual Life Res. 2018;27(10):2557-2570. doi:10.1007/s11136-018-1916-2

4. Hoekman DR, Rutten JMTM, Vlieger AM, Benninga MA, Dijkgraaf MGW. Annual costs of care for pediatric irritable bowel syndrome, functional abdominal pain, and functional abdominal pain syndrome. J Pediatr. 2015;167(5):1103-1108. doi:10.1016/j.jpeds.20 15.07 .058

5. Abbott RA, Martin AE, Newlove-Delgado TV, et al. Psychosocial interventions for recurrent abdominal pain in childhood. Cochrane Database Syst Rev. 2017;10(1):CD010971.

6. Peng P, Choiniere M, Dion D, et al. Challenges in accessing multidisciplinary pain treatment facilities in Canada. Can $J$ Anaesth. 2007;54(12):977-984. doi:10.1007/BF03016631

7. Loeser JD. Five crises in pain management. Pain Clin Updat. 2012;20:1-4.

8. Twycross A, Roderique L. Review of pain content in three-year preregistration pediatric nursing courses in the United Kingdom. Pain Manag Nurs. 2013;14(4):247-258. doi:10.1016/j.pmn.2011.05. 002

9. Nieto R. Secondary prevention of chronic pain: can internet help? Pain Manag. 2014;4(4). doi:10.2217/pmt.14.22

10. Van Beugen S, Ferwerda M, Hoeve D, et al. Internet-based cognitive behavioral therapy for patients with chronic somatic conditions: a meta-analytic review. J Med Internet Res. 2014;16(3):e88. doi:10.2196/ jmir.2777

11. Beatty L, Lambert S. A systematic review of internet-based self-help therapeutic interventions to improve distress and disease-control among adults with chronic health conditions. Clin Psychol Rev. 2013;33(4):609-622. doi:10.1016/j.cpr.2013.03.004

12. Keogh E. Developments in the use of e-health for chronic pain management. Pain Manag. 2013;3(1):27-33. doi:10.2217/pmt.12.70

13. Keogh E, Rosser BA, Eccleston C. e-Health and chronic pain management: current status and developments. Pain. 2010;151(1):18-21. doi:10.1016/j.pain.2010.07.014

14. Eccleston C, Fisher E, Craig L, Duggan GB, Rosser BA, Keogh E. Psychological therapies (Internet-delivered) for the management of chronic pain in adults. Cochrane Database Syst Rev. 2014;26(2): CD010152.

15. Barak A, Klein B, Proudfoot JG. Defining internet-supported therapeutic interventions. Ann Behav Med. 2009;38(1):4-17. doi:10.1007/ s12160-009-9130-7

16. Murray E. Web-based interventions for behavior change and self-management: potential, pitfalls, and progress. $J$ Med Internet Res. 2012;14(4):e3.

17. Trautmann E, Kröner-Herwig B. A randomized controlled trial of Internet-based self-help training for recurrent headache in childhood and adolescence. Behav Res Ther. 2010;48(1):28-37. doi:10.1016/j. brat.2009.09.004

18. Law EF, Beals-Erickson SE, Noel M, Claar R, Palermo TM. Pilot randomized controlled trial of internet-delivered cognitive-behavioral treatment for pediatric headache. Headac. 2015;55(10):1410-1425. doi:10.1111/head.12635 
19. Stinson JN, McGrath PJ, Hodnett ED, et al. An internet-based self-management program with telephone support for adolescents with arthritis: a pilot randomized controlled trial. J Rheumatol. 2010;37(9):1944-1952. doi:10.3899/jrheum.091327

20. Hicks CL, von Baeyer CL, McGrath PJ. Online psychological treatment for pediatric recurrent pain: a randomized evaluation. $J$ Pediatr Psychol. 2006;31(7):724-736. doi:10.1093/jpepsy/jsj065

21. Palermo TM, Wilson AC, Peters M, Lewandowski A, Somhegyi H Randomized controlled trial of an Internet-delivered family cognitive-behavioral therapy intervention for children and adolescents with chronic pain. Pain. 2009;146(1-2):205-213. doi:10.1016/j. pain.2009.07.034

22. Voerman JS, Remerie S, Westendorp T, et al. Effects of a guided internet-delivered self-help intervention for adolescents with chronic pain. J Pain. 2015;16(11):1115-1126. doi:10.1016/j.jpain.2015.07.011

23. Palermo TM, Law E, Fales J, Bromberg M, Jessen-Fiddick T, Tai G. Internet-delivered cognitive-behavioral treatment for adolescents with chronic pain and their parents: a randomized controlled multicenter trial. Pain. 2016;157:174-185. doi:10.1097/j.pain.0000000 000000348

24. Nieto R, Hernández E, Boixadós M, Huguet A, Beneitez I, McGrath P. Testing the Feasibility of DARWeb. Clin J Pain. 2015;31(6):493-503. doi:10.1097/AJP.0000000000000199

25. Nieto R, Hernández E, Boixadós M, Beneitez I, Beneitez I, McGrath P. Quantitative and qualitative testing of DARWeb: an online self-guided intervention for children with functional abdominal pain and their parents. Health Informatics J. 2019;25 (4):1511-1527. doi:10.1177/1460458218779113

26. O'Cathain A, Thomas KJ, Drabble SJ, Rudolph A, Hewison J. What can qualitative research do for randomised controlled trials? A systematic mapping review. BMJ Open. 2013;3:6.

27. Wozney L, McGrath PJ, Newton A, et al. Usability, learnability and performance evaluation of Intelligent Research and Intervention Software: a delivery platform for eHealth interventions. Health Informatics $J$. 2015;22(3):730-743. doi:10.1177/1460458215586803

28. Suresh K. An overview of randomization techniques: an unbiased assessment of outcome in clinical research. J Hum Reprod Sci. 2011;4(1):8. doi:10.4103/0974-1208.82352

29. Apley J, Naish N. Recurrent abdominal pains: a field survey of 1000 school children. Arch Dis Child. 1958;33(168):165-170. doi:10.1136/ adc.33.168.165

30. Huguet A, Miró J. The severity of chronic pediatric pain: an epidemiological study. J Pain. 2008;9(3):226-236. doi:10.1016/j.jpain.2007.10.015

31. Pita S. Determinación del tamaño muestral. Cad Aten Primaria 1996;3:138-141.

32. Palermo TM, Eccleston C, Lewandowski AS, Williams AC, Morley S. Randomized controlled trials of psychological therapies for management of chronic pain in children and adolescents: an updated meta-analytic review. Pain. 2010;148:387-397. doi:10.1016/j.pain.2009.10.004

33. Fisher E, Heathcote L, Palermo TM, Williams AC, Lau J, Eccleston C. Systematic review and meta-analysis of psychological therapies for children with chronic pain. J Pediatr Psychol. 2014;39 (8):763-782. doi:10.1093/jpepsy/jsu008

34. McGrath PJ, Walco GA, Turk DC, et al. Core outcome domains and measures for pediatric acute and chronic/recurrent pain clinical trials: pedIMMPACT recommendations. $J$ Pain. 2008;9:771-783. doi:10.1016/j.jpain.2008.04.007

35. Walker LS, Garber J, Greene JW. Somatization symptoms in pediatric abdominal-pain patients - relation to chronicity of abdominal-pain and parent somatization. J Abnorm Child Psychol. 1991;19 (4):379-394. doi:10.1007/BF00919084

36. Salvador $\mathrm{T}$ Dolor abdominal crónico en la edad pediátrica: implicación de factores clínicos, ambientales y psicosociales. Desarrollo de un programa informático especifico. $[\mathrm{PhD}$ Dissertation]. University of Valencia; 2015.
37. Laird KT, Sherman AL, Smith CA, Walker LS. Validation of the Abdominal Pain Index using a revised scoring method. J Pediatr Psychol. 2015;40(5):517-525. doi:10.1093/jpepsy/jsu118

38. Robins PM, Smith SM, Glutting JJ, Bishop CT. A randomized controlled trial of a cognitive-behavioral family intervention for pediatric recurrent abdominal pain. J Pediatr Psychol. 2005;30(5):397-408. doi:10.1093/jpepsy/jsi063

39. van der Veek SMC, Derkx BHF, Benninga MA, Boer F, de Haan E. Cognitive behavior therapy for pediatric functional abdominal pain: a randomized controlled trial. Pediatrics. 2013;132(5):e1163-72. doi:10.1542/peds.2013-0242

40. Walker LS, Garber J. Psychosocial correlates of recurrent childhood pain: a comparison of pediatric patients with recurrent abdominal pain, organic illness, and psychiatric disorders. J Abnorm Psychol. 1993;102(2):248-258. doi:10.1037/0021-843X. 102.2 .248

41. Wallander JL, Madan-Swain A, Klapow J, Saeed S. A randomised controlled trial of written self-disclosure for functional recurrent abdominal pain in youth. Psychol Heal. 2011;26(4):433-447. doi:10.1080/08870440903477212

42. Huguet A, Miró J. Development and psychometric evaluation of a Catalan self- and interviewer-administered version of the Pediatric Quality of Life Inventory version 4.0. J Pediatr Psychol. 2008;33 (1):63-79. doi:10.1093/jpepsy/jsm040

43. Kovacs M. The Children's Depression, Inventory (CDI) Psychopharmacol Bull. 1985;21(4):995-998.

44. Frías-Navarro D, Del Barrio V, Mestre V. Children's Depression Inventory (CDI): sus características psicométricas en población extranjera y española. Evaluación Psicológica. 1991;7(3):377-391.

45. Figueras A, Amador-Campos J, Gómez-Benito J, Barrio V. Psychometric properties of the Children's Depression Inventory in community and clinical sample. Span J Psychol. 2010;13 (2):990-999. doi:10.1017/S1138741600002638

46. Walker LS, Greene JW. The functional disability inventory: measuring a neglected dimension of child health status. J Pediatr Psychol. 1991;16(1):39-58. doi:10.1093/jpepsy/16.1.39

47. Solé E, Galán S, de la Vega R, et al. Psychometric properties of the Functional Disability Inventory for assessing pain-related disability in children from the community. Disabil Rehabil. 2019;41 (20):2451-2458. doi:10.1080/09638288.2018.1467969

48. Crombez G, Bijttebier P, Eccleston C, et al. The child version of the Pain Catastrophizing Scale (PCS-C): a preliminary validation. Pain. 2003;104:639-646. doi:10.1016/S0304-3959(03)00121-0

49. Solé E, Castarlenas E, Miró J. A catalan adaptation and validation of the pain catastrophizing scale for children. Psychol Assess. 2016;28 (6):e119-e126. doi:10.1037/pas0000243

50. Reid GJ, Gilbert CA, McGrath PJ. The pain coping questionnaire: preliminary validation. Pain. 1998;76(1-2):83-96. doi:10.1016/ S0304-3959(98)00029-3

51. Huguet A, Miró J, Nieto R. The factor structure and factorial invariance of the Pain-Coping Questionnaire across age: evidence from community-based samples of children and adults. Eur J Pain. 2009;13(8):879-889. doi:10.1016/j.ejpain.2008.10. 004

52. Huguet A, Miró J, Nieto R. The Inventory of Parent/Caregiver Responses to the Children's Pain Experience (IRPEDNA): development and preliminary validation. Pain. 2008;134(1-2):128-139. doi:10.1016/j.pain.2007.04.004

53. Alfvén G, Lindstrom A. A new method for the treatment of recurrent abdominal pain of prolonged negative stress origin. Acta Paediatr. 2007;96(1):76-81. doi:10.1111/apa.2007.96.issue-1

54. Hechler T, Ruhe A-K, Schmidt $\mathrm{P}$, et al. Inpatient-based intensive interdisciplinary pain treatment for highly impaired children with severe chronic pain: randomized controlled trial of efficacy and economic effects. Pain. 2014;155(1):118-128. doi:10.1016/j.pain.20 13.09 .015 
55. Wassom MC, Schurman JV, Friesen CA, Rapoff MA. A pilot study of "Gutstrong" for adolescents with functional gastrointestinal disorders. Clin Pract Pediatr Psychol. 2013;1(3):201-213. doi:10.1037/ cpp0000025

56. Groß M, Warschburger P. Evaluation of a cognitive-behavioral pain management program for children with chronic abdominal pain: A randomized controlled study. Int $J$ Behav Med. 2013;20 (3):434-443. doi:10.1007/s12529-012-9228-3

57. Madill A, Gough B. Qualitative research and its place in psychological science. Psychol Methods. 2008;13(3):254-271. doi:10.1037/ a0013220
58. Nieto R, Sora B, Ruiz G. Giving less importance to pain and focusing on achieving objectives. Pain Manag. 2019;9(1):45-52. doi:10.2217/ pmt-2018-0044

59. van Tilburg MAL, Chitkara DK, Palsson OS, et al. Audio-recorded guided imagery treatment reduces functional abdominal pain in children: A pilot study. Pediatrics. 2009;124(5):e890-e897. doi:10.1542/ peds.2009-0028

60. Levy RL, Langer SL, Walker LS, et al. Cognitive-behavioral therapy for children with functional abdominal pain and their parents decreases pain and other symptoms. Am J Gastroenterol. 2010;105 (4):946-956. doi:10.1038/ajg.2010.106

\section{Publish your work in this journal}

The Journal of Pain Research is an international, peer reviewed, open access, online journal that welcomes laboratory and clinical findings in the fields of pain research and the prevention and management of pain. Original research, reviews, symposium reports, hypothesis formation and commentaries are all considered for publication. The manuscript management system is completely online and includes a very quick and fair peer-review system, which is all easy to use. Visit http:// www.dovepress.com/testimonials.php to read real quotes from published authors. 